\title{
A Comparative Study of Overall Stability Calculation of Bending Members by Specifications for Design of Steel Structures Between China and USA
}

\author{
Zhou Kongpei* and Pu Wanli
}

School of Civil Engineering and Architecture, Southwest Petroleum University, Xindu 610500, China

\begin{abstract}
For the issues of overall stability design of bending members in the three specifications for design of steel structures GB 50017-2003, GB 50017-201X(exposure draft) and AISC 360-10, we compared the detailed differences between the three specifications mainly from the aspect of calculation principle of the critical moment $M_{c r}$ and stability design formulas. The differences can be compared and obtained by applying the design methods to practical problems of stability design of bending members. On the other hand, it can provide some references for the subsequent revision of Chinese code for design of steel structures.
\end{abstract}

Keywords: Flexural-torsional buckling; critical moment; equivalent moment factor; specifications between China and USA.

\section{INTRODUCTION}

For the bending beam in the plane, when the moment of the beam $M<M_{c r}\left(M_{c r}\right.$ is called the critical moment), the beam produces only bending deformation in the plane of moment, with no lateral deformation. Even at this time there is outside accidental lateral disturbance force on the beam, bringing a certain degree of lateral displacement and torsion. But when the disturbance force disappears, the beam can still return to the original state of stable equilibrium. This phenomenon is called the overall stability of the beam. When $M \geq M_{c r}$, the beam will suddenly occur lateral bending and torsion under the action of a small lateral disturbance force. Besides, the torsion deformation does not disappear even by removing the lateral disturbance force. The beam lost carrying capacity with the increase of moment. This phenomenon is overall unstability, also called lateraltorsional buckling of the beam [1].

For the biaxial symmetry and uniform bending charpy in Fig. (1), the critical moment is:

$M_{c r}=\frac{\pi}{l} \sqrt{E I_{y} G I_{t}\left(1+\frac{\pi^{2} E I_{\omega}}{G I_{t} l^{2}}\right)}$

For the biaxial symmetry and non-uniform bending charpy(the end moment $M_{1}$ and $M_{2}$ is not equal) in Fig. (2), the critical moment is:

*Address correspondence to this author at the School of Civil Engineering and Architecture, Southwest Petroleum University, Xindu 610500,China: Tel: 15828646271: E-mails: 492184004@qq.com; zhou21010@sina.com

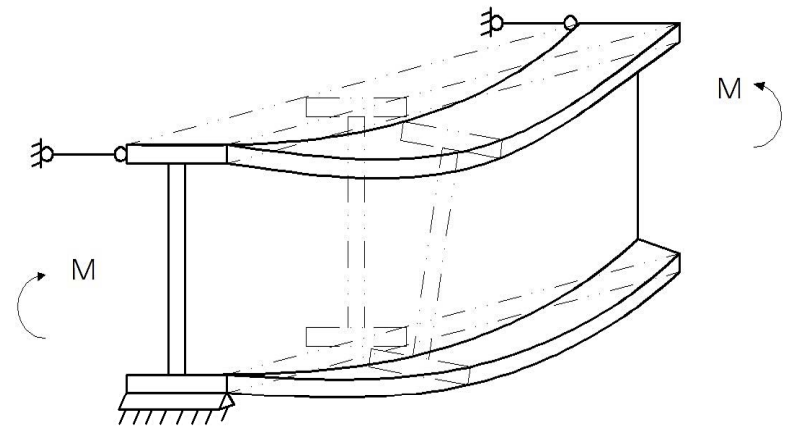

Fig. (1). Flexural-torsional buckling of beam.

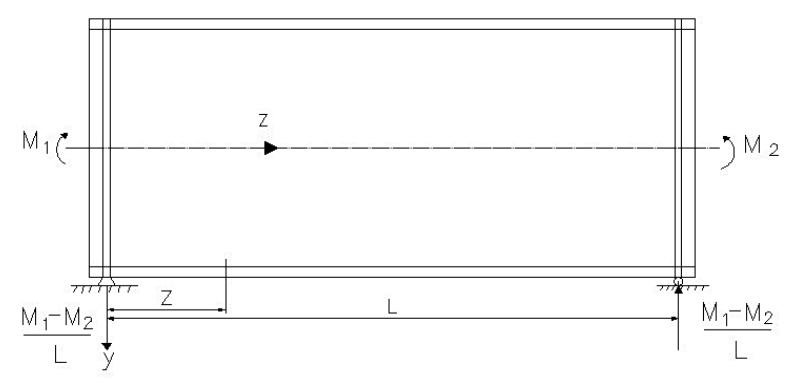

Fig. (2). Bending beam with unequal end moment.

$$
M_{c r}=\beta_{b} \frac{\pi}{l} \sqrt{E I_{y} G I_{t}\left(1+\frac{\pi^{2} E I_{\omega}}{G I_{t} l^{2}}\right)}
$$


Here $\beta_{b}$ is the equivalent moment factor of bending members.

The current specification for steel structures of China is GB 50017-2003 [2], having been used for 10 years. In recent years, the relevant departments have been committed to the revision of new specification. Then GB 50017-201X (exposure draft) [3] has been released in June 2012. The draft has passed the expert group discussions and it is being approved by the higher authorities now. The current specification for steel structures in USA is AISC 360-10 Specification for Structural Steel Buildings [4], which was being revised on the basis of AISC 360-05. For the calculation method of overall stability of bending members in the three specifications, we have made a detailed comparison in the following content.

\section{THE COMPARISON OF CRITICAL MOMENT $M_{c r}$ AND EQUIVALENT MOMENT FACTOR $\beta_{b}$ BE- TWEEN GB 50017-2003 AND GB 50017-201X}

Chinese code has been revised for the calculation method of overall stability factor $\varphi_{b}$ with respect to the overall stability design of flexural members. GB 50017-201X(exposure draft), which is being approved, is not only revised for the calculation method of overall stability factor $\varphi_{b}$, but also has changed in the overall stability design formula compared with GB 50017-2003. From TJ 17-74 to GB 50017-2003, the equivalent moment factor $\beta_{b}$ has been using the lower limit (formula 3) in equivalent moment factor $\beta_{b}$ curve of hinged non-uniform flexural members, which was studied by M. G. Salvadori [5] in 1956. The revised overall stability formula in GB 50017-201X is not related to $\beta_{b}$

$\beta_{b}=1.75-1.05 \frac{M_{2}}{M_{1}}+0.3\left(\frac{M_{2}}{M_{1}}\right)^{2} \leq 2.3$

Here, $M_{1}$ and $M_{2}$ are the end moments. When they cause the member to generate curvature distortion in the same direction in the moment plane, they take the same sign, and $M_{1} \geq M_{2}$; when they cause the member to generate curvature distortion in different direction, they take the opposite sign, and $\left|M_{1}\right| \geq\left|M_{2}\right|$.

Besides, Professor Tong Genshu [6] proposes that the following formula may also be used:

$\beta_{b}=1.84-0.84 \sin \left(0.5 \pi M_{2} / M_{1}\right)$

In GB 50017-2003 Appendix B and Table B, another calculation method of charpy equivalent moment factor $\beta_{b}$ for the H-beam and the I-beam with uniform section is given. The formula $\varepsilon=l_{1} t_{1} / b_{1} h$, here $l_{1}$ is the lateral free length of compression flange, $b_{1}$ and $t_{1}$ are the width and thickness of the compression flange, $h$ is the section height.

The elastic flexural-torsional buckling calculation of bending members in GB 50017-2003 is based on the formula of critical moment $M_{c r}$ which is under concentrated transverse loads [7].

$M_{c r}=\beta_{1} \frac{\pi^{2} E I_{y}}{l_{y}^{2}}\left[\beta_{2} a+\beta_{3} \beta_{y}+\sqrt{\left(\beta_{2} a+\beta_{3} \beta_{y}\right)^{2}+\frac{I_{\omega}}{I_{y}}\left(1+\frac{G I_{t} l_{w}^{2}}{\pi^{2} E I_{w}}\right)}\right]$

Here the correction factor $\beta_{1}=\beta_{3}=1.0, \beta_{2}=0$, so the stability factor of flexural-torsional buckling is $\varphi_{0 b}=M_{0 c r} /\left(W_{x} f_{y}\right)$, then:

$\varphi_{0 b}=\frac{\pi^{2} E I_{y}}{l^{2} W_{x} f_{y}}\left[\beta_{y}+\sqrt{\beta_{y}^{2}+\frac{I_{\omega}}{I_{y}}\left(1+\frac{G I_{t} l^{2}}{\pi^{2} E I_{w}}\right)}\right]$

We can get this by simplifying and substituting:

$\varphi_{0 b}=\frac{4320 A h}{\lambda_{y}{ }^{2} W_{x}}\left[\eta_{b}+\sqrt{1+\left(\frac{\lambda_{y} t_{1}}{4.4 h}\right)^{2}}\right] \frac{235}{f_{y}}$

At last the stability factor of elastic flexural-torsional buckling is this:

$\varphi_{b}=\beta_{b} \varphi_{0 b}=\beta_{b} \frac{4320 A h}{\lambda_{y}{ }^{2} W_{x}}\left[\eta_{b}+\sqrt{1+\left(\frac{\lambda_{y} t_{1}}{4.4 h}\right)^{2}}\right] \frac{235}{f_{y}}$

Besides, when $\varphi_{b} \geq 0.6$, there need for a correction:

$\varphi_{b}^{\prime}=1.07-0.282 / \varphi_{b}$ is:

The overall stability design formula in GB 50017-2003

$M_{x} \leq \varphi_{b} W_{x} f$

But in GB 50017-201X(exposure draft), it makes modification in overall stability design formula based on formula(8):

$M_{x} \leq \varphi_{b} \gamma_{x} f W_{x}$

It can be seen that the new overall stability design formula(9) has a section plasticity development factor $\gamma_{x}$ compared with formula(8). For the I-section and box section, we take $\gamma_{X}=1.05$.

The overall stability factor $\varphi_{b}$ in GB 50017-201X is very different from GB 50017-2003. The new formula of overall stability factor $\varphi_{b}$ is:

$\varphi_{b}=\frac{1}{\left(1-\lambda_{b 0}^{2 n}+\lambda_{b}^{2 n}\right)^{1 / n}} \leq 1.0$

Here, $n$ and $\lambda_{b 0}$ are determined by the formula in Fig. (3). $\lambda_{b}$ is determined by the following formula:

$\lambda_{b}=\sqrt{\frac{\gamma_{x} W_{x} f_{y}}{M_{c r}}}$

$M_{c r}$ is the elastic buckling critical moment of charpy, cantilever beam or continuous beam. The formula is: 


\begin{tabular}{|c|c|c|c|}
\hline & & $\lambda_{b 0}$ & $\lambda_{b 0}$ \\
\hline & & charpy & bearing linear change moment \\
\hline hot rolled & $2.5 \sqrt[3]{\frac{b_{1}}{h}}$ & 0.4 & $0.65-0.25 \frac{M_{2}}{M_{1}}$ \\
\hline welding & $1.8 \sqrt[3]{\frac{b_{1}}{h}}$ & 0.3 & $0.55-0.25 \frac{M_{2}}{M_{1}}$ \\
\hline
\end{tabular}

Fig. (3). The formula of $n$ and $\lambda_{b 0}$.

$M_{c r}=C_{1} \frac{\pi^{2} E I_{y}}{l^{2}}\left[-C_{2} a+C_{3} \beta_{x}+\sqrt{\left(-C_{2} a+C_{3} \beta_{x}\right)^{2}+\frac{I_{\omega}}{I_{y}}\left(1+\frac{l^{2} G J}{\pi^{2} E I_{\omega}}\right)}\right]$

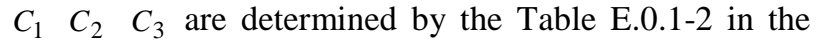
appendix. $\beta_{X}$ is the section asymmetry parameter. When the section is biaxial symmetry, $\beta_{X}=0$.

For a long time, our country does not distinguish the overall stability factor between welding beams and rolled beams. However, their overall stability factors are not the same in practical experiments. So GB 50017-201X refers to the research achievements of UK, Japan and other countries in this respect, and it distinguishes the overall stability factor between welding beams and rolled beams for the first time.

It can be seen that the overall stability design thinking of GB 50017-2003 and GB 50017-201X is the same: translating critical moment into overall stability factor $\varphi_{b}$ and using $\varphi_{b}$ into overall stability design formula. GB 50017-201X has changed in the determination of $\varphi_{b}$ and overall stability design formula. Therefore the determination of overall stability factor $\varphi_{b}$ is the core.

\section{CRITICAL MOMENT $M_{c r}$ AND EQUIVALENT} MOMENT FACTOR $\beta_{b}$ IN AISC 360-10 SPECIFICATION FOR STRUCTURAL STEEL BUILDINGS

The calculation of equivalent moment factor $\beta_{b}$ in AISC $360-10$ is totally different from our country's GB 500172003 and GB 50017-201X. It was based on the moment distribution map of unbraced length beam segment [8] (Fig. 4),

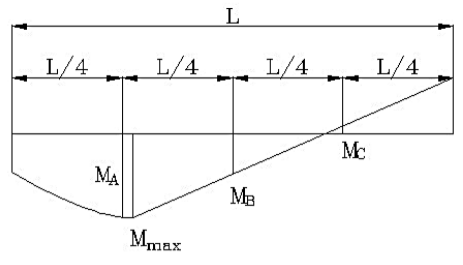

a which was proposed by P. A. Kirby and D. A. Nethercot in 1979. Later AISC 360-10 got the formula of $\beta_{b}$ on the basis of making corrections on the first formula proposed by P. A. Kirby and D. A. Nethercot. The formula of $\beta_{b}$ in AISC 36010 is:

$$
\beta_{b}=\frac{12.5 M_{\max }}{2.5 M_{\text {max }}+3 M_{A}+4 M_{B}+3 M_{C}} \leq 3.0
$$

Here, $M_{\max }$ is absolute value of maximum moment in the unbraced segment; $M_{A}$ is absolute value of moment at quarter point of the unbraced segment; $M_{B}$ is the absolute value of moment at centerline of the unbraced segment; $M_{C}$ is absolute value of moment at three-quarter point of the unbraced segment.

For the doubly symmetric compact I-shaped members and channels bent about their major axis, having compact webs and compact flanges, AISC 360-10 gives the following formula of critical moment $M_{c r}$. It divides the lateraltorsional buckling into three different states on the basis of three kinds of relationships between $L_{b}, L_{p}$ and $L_{r}$ [9]:

(1) when $L_{b} \leq L_{p}$, the limit state of lateral-torsional buckling does not apply. At this point it means the same with 4.2.1 in GB 50017-2003 and 7.2.1 in GB 50017-201X.

(2) when

$$
L_{p}<L_{b} \leq L_{r},
$$

$$
M_{c r}=\beta_{b}\left[M_{p}-\left(M_{p}-0.7 F_{y} S_{x}\right)\left(\frac{L_{b}-L_{p}}{L_{r}-L_{p}}\right)\right] \leq M_{p},
$$

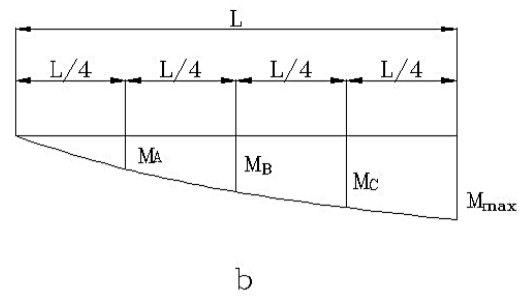

Fig. (4). Moment distribution map of unbraced length beam segment. 
that is to take the smaller one between $\beta_{b}\left[M_{p}-\left(M_{p}-0.7 F_{y} S_{x}\right)\left(\frac{L_{b}-L_{p}}{L_{r}-L_{p}}\right)\right]$ and $M_{p}$;

(3) when $L_{b}>L_{r}, M_{c r}=F_{c r} S_{x} \leq M_{p}$;

Here, $\quad F_{c r}=\frac{\beta_{b} \pi^{2} E}{\left(\frac{L_{b}}{r_{t s}}\right)^{2}} \sqrt{1+0.078 \frac{J_{C}}{S_{x} h_{0}}\left(\frac{L_{b}}{r_{t s}}\right)^{2}}$, $L_{p}=1.76 r_{y} \sqrt{\frac{E}{F_{y}}}$,

$L_{r}=1.95 r_{t s} \frac{E}{0.7 F_{y}} \sqrt{\frac{J_{C}}{S_{x} h_{0}}} \sqrt{1+\sqrt{1+6.76\left(\frac{0.7 F_{y}}{E} \frac{S_{x} h_{0}}{J_{C}}\right)^{2}}}$, $r_{t s}^{2}=\frac{\sqrt{I_{y} C_{w}}}{S_{x}}$

The overall stability design formula of bending members in AISC 360-10 is:

$M_{x} \leq \phi_{b} M_{c r}$

Here, $\phi_{b}=0.9$.

According to formula(12), it can be seen that critical moment $M_{c r}$ is used for overall stability design formula directly. So the determination of critical moment $M_{c r}$ is the core of overall stability design. On this point it is obviously different from our country’s GB 50017-2003 and GB 50017201X.

\section{THE COMPARISON BETWEEN THE THREE SPECIFICATIONS IN THE ACTUAL DESIGN}

For example, there is an I-shaped beam having compact webs and compact flanges, simply supported at both ends, in Fig. (5). We calculate the design value of critical moment by respectively using GB 50017-201X, GB 50017-2003 and AISC 360-10. Here, the steel model is Q235, $f_{y}=235 \mathrm{MPa}$, the design strength $f=215 \mathrm{MPa}, \mathrm{E}=206000 \mathrm{MPa}, \mathrm{G}=79000-$ MPa. We separately do the calculation for the two kinds of cross section in Fig. (6).

1. For the doubly symmetric cross section

The parameters of the beam section obtained by calculation

are: $A=128 \mathrm{~cm}^{2}, I_{X}=99096.2 \mathrm{~cm}^{4}, W_{X}=2984.8 \mathrm{~cm}^{3}$,

$W_{p x}=3322.9 \mathrm{~cm}^{3}, I_{t}=47.8 \mathrm{~cm}^{4}$,

$I_{y}=6553.6 \mathrm{~cm}^{4}, r_{y}=7.16 \mathrm{~cm}, I_{w}=6964904 \mathrm{~cm}^{6}, l_{y}=450 \mathrm{~cm}$, $\lambda_{y}=62.8, M_{p x}=780.9 \mathrm{KN} . \mathrm{m}$.

(1) GB 50017-201X

The calculation of overall stability factor $\varphi_{b}$ :

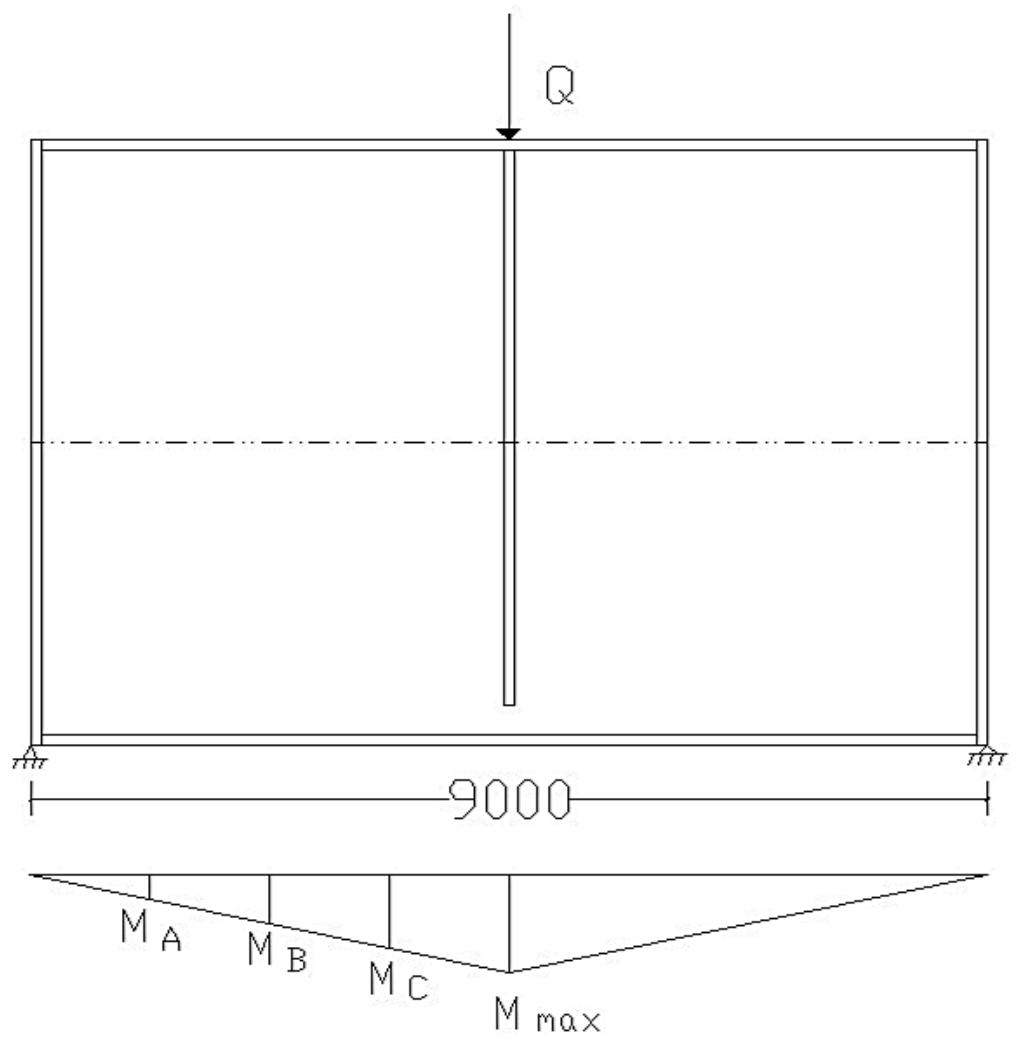

Fig. (5). The I-shaped beam. 

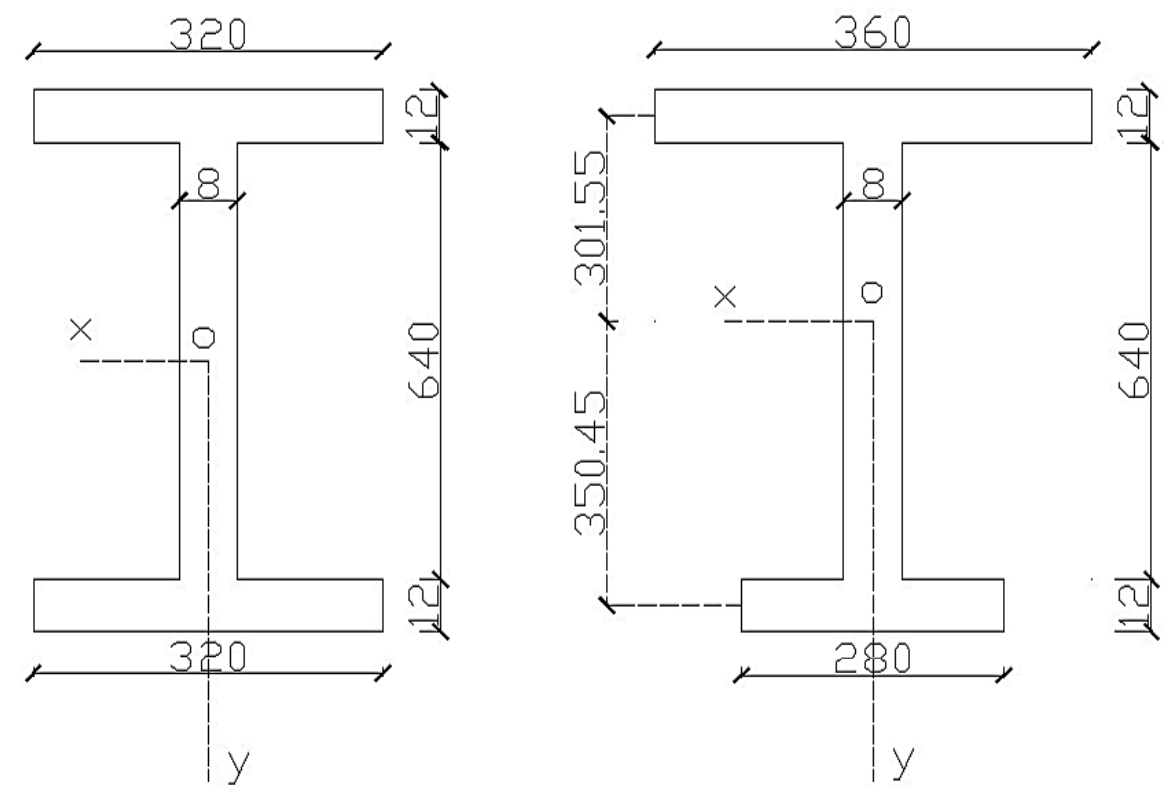

Fig. (6). Doubly symmetric and singly symmetric I-shaped cross section.

a. if it is rolled beam, according to the formula in Fig. (3),

$n=2.5 \sqrt[3]{\frac{b_{1}}{h}}=2.5 \times \sqrt[3]{\frac{320}{652}}=1.972, \lambda_{b 0}=0.4$

According to the Table E.0.1-2 in Appendix E in GB 50017-201X, $C_{1}=1.75, C_{2}=0, C_{3}=1, \beta_{x}=0$, so:

$M_{c r}=1.75 \frac{\pi^{2} E I_{y}}{l^{2}} \sqrt{\frac{I_{w}}{I_{y}}\left(1+\frac{l^{2} G I_{t}}{\pi^{2} E I_{w}}\right)}=3854 K N \cdot m$

$\lambda_{b}=\sqrt{\frac{\gamma_{x} W_{x} f_{y}}{M_{c r}}}=0.437, \varphi_{b}=\frac{1}{\left(1-\lambda_{b 0}^{2 n}+\lambda_{b}^{2 n}\right)^{1 / n}}=0.994$

Substituting into the formula(9), the design value of critical moment is:

$M_{X} \leq \varphi_{b} \gamma_{x} f W_{x}=0.994 \times 1.05 \times 215 \mathrm{MPa} \times 2984.8 \mathrm{~cm}^{3}=670 \mathrm{KN} \cdot \mathrm{m}$

b. if it is welding beam, then, $n=1.8 \sqrt[3]{\frac{b_{1}}{h}}=1.8 \times \sqrt[3]{\frac{320}{652}}=1.42$, $\lambda_{b 0}=0.3$

$M_{c r}=3854 K N \cdot m, \lambda_{b}=0.437$ is the same with rolled beam.

$\varphi_{b}=\frac{1}{\left(1-\lambda_{b 0}^{2 n}+\lambda_{b}^{2 n}\right)^{1 / n}}=0.958$

The design value of critical moment is:

$M_{x} \leq \varphi_{b} \gamma_{x} f W_{x}=0.958 \times 1.05 \times 215 \mathrm{MPa} \times 2984.8 \mathrm{~cm}^{3}=645.6 \mathrm{KN} \cdot \mathrm{m}$

So, it can be seen that the overall stability factor $\varphi_{b}$ of welding beams is lower than rolled beams. Thus, the design value of critical moment of welding beams is lower than rolled beams.
(2) GB 50017-2003

According to the Table B.1 in Appendix B in GB 500172003, we take the equivalent moment factor $\beta_{b}=1.75$; It can also get $\beta_{b}=1.75$ by formula(3) because the end moment $M_{1}$ and $M_{2}$ are both zero. Substituting into the formula(6):

$$
\begin{aligned}
& \varphi_{b}=\beta_{b} \frac{4320 A h}{\lambda_{y}{ }^{2} W_{x}}\left[\eta_{b}+\sqrt{1+\left(\frac{\lambda_{y} t_{1}}{4.4 h}\right)^{2}}\right] \frac{235}{f_{y}}=5.637>0.6, \\
& \varphi_{b}^{\prime}=1.07-\frac{0.282}{\varphi_{b}}=1.0
\end{aligned}
$$

The design value of critical moment is:

$M_{x} \leq \varphi_{b}^{\prime} W_{x} f=1.0 \times 2984.8 \mathrm{~cm}^{3} \times 215 \mathrm{MPa}=641.7 \mathrm{KN} \cdot \mathrm{m}$

(3) AISC 360-10

We can get $M_{A}: M_{B}: M_{C}: M_{M A X}=1: 2: 3: 4$ according to the moment distribution map in Fig. (5), then substituting into the formula(11), so $\beta_{b}=1.667$.

$$
\begin{aligned}
& L_{b}=450 \mathrm{~cm}, L_{p}=1.76 r_{y} \sqrt{\frac{E}{F_{y}}}=373.1 \mathrm{~cm}, \\
& r_{t s}=\sqrt{\frac{\sqrt{I_{y} I_{w}}}{W_{x}}}=8.46 \mathrm{~cm} \\
& L_{r}=1.95 r_{t s} \frac{E}{0.7 F_{y}} \sqrt{\frac{J_{C}}{S_{x} h_{0}}} \sqrt{1+\sqrt{1+6.76\left(\frac{0.7 F_{y}}{E} \frac{S_{x} h_{0}}{J_{C}}\right)^{2}}}=997.8 \mathrm{~cm}
\end{aligned}
$$

Because $L_{p}<L_{b} \leq L_{r}$, so the formula of critical moment is: 
$M_{c r}=\beta_{b}\left[M_{p}-\left(M_{p}-0.7 F_{y} S_{x}\right)\left(\frac{L_{b}-L_{p}}{L_{r}-L_{p}}\right)\right]=1242.1 K N$

$m>M_{p x}=780.9 \mathrm{KN} \cdot \mathrm{m}$

Because when $L_{p}<L_{b} \leq L_{r}, \quad M_{c r} \leq M_{p x}, \quad$ so $M_{c r}=780.9 \mathrm{KN} \cdot \mathrm{m}$

Substituting into the formula (12):

$$
M_{x} \leq \phi_{b} M_{c r}=0.9 \times 780.9 K N \cdot m=702.8 K N \cdot m
$$

So the design value of critical moment is $702.8 \mathrm{KN} \cdot \mathrm{m}$.

2. For the singly symmetric cross section tion

The parameters of the beam section obtained by calculaare: $A=128 \mathrm{~cm}^{2}, I_{x}=98331 \mathrm{~cm}^{4}, W_{x}=2758.6 \mathrm{~cm}^{3}$, $W_{p x}=3304.2 \mathrm{~cm}^{3}, I_{t}=47.8 \mathrm{~cm}^{4}$, $I_{y}=6860.8 \mathrm{~cm}^{4}, r_{y}=7.32 \mathrm{~cm}, I_{w}=6346029 \mathrm{~cm}^{6}, l_{y}=450 \mathrm{~cm}$, $\lambda_{y}=61.5, M_{p x}=776.5 \mathrm{KN} . \mathrm{m}$.

\section{(1) GB 50017-201X}

The calculation of overall stability factor $\varphi_{b}$ :

a. if it is rolled beam, according to the formula in Fig. (3), $n=2.5 \sqrt[3]{\frac{b_{1}}{h}}=2.5 \times \sqrt[3]{\frac{360}{652}}=2.05, \lambda_{b 0}=0.4$

According to the Table E.0.1-2 in Appendix E in GB 50017-201X, $C_{1}=1.75, C_{2}=0, C_{3}=1$,

We get $\beta_{x}=10.96 \mathrm{~cm}$, so formula E.0.1-1 becomes:

$M_{c r}=1.75 \frac{\pi^{2} E I_{y}}{l^{2}}\left[\beta_{x}+\sqrt{\beta_{x}^{2}+\frac{I_{w}}{I_{y}}\left(1+\frac{l^{2} G I_{t}}{\pi^{2} E I_{w}}\right)}\right]=5318.5 \mathrm{KN} \cdot \mathrm{m}$ $\lambda_{b}=\sqrt{\frac{\gamma_{x} W_{x} f_{y}}{M_{c r}}}=0.358, \varphi_{b}=\frac{1}{\left(1-\lambda_{b 0}^{2 n}+\lambda_{b}^{2 n}\right)^{1 / n}}=1.0$

Substituting into the formula(9), the design value of critical moment is:

$M_{X} \leq \varphi_{b} \gamma_{X} f W_{X}=1.0 \times 1.05 \times 215 \mathrm{MPa} \times 2758.6 \mathrm{~cm}^{3}=622.8 \mathrm{KN} \cdot \mathrm{m}$

b. if it is welding beam, then, $n=1.8 \sqrt[3]{\frac{b_{1}}{h}}=1.8 \times \sqrt[3]{\frac{360}{652}}=1.48$, $\lambda_{b 0}=0.3$

$M_{c r}=5318.5 \mathrm{KN} \cdot \mathrm{m}, \quad \lambda_{b}=0.358$ is the same with rolled beam.

$\varphi_{b}=\frac{1}{\left(1-\lambda_{b 0}^{2 n}+\lambda_{b}^{2 n}\right)^{1 / n}}=0.987$

The design value of critical moment is:

$M_{X} \leq \varphi_{b} \gamma_{X} f W_{X}=0.987 \times 1.05 \times 215 \mathrm{MPa} \times 2758.6 \mathrm{~cm}^{3}=614.7 \mathrm{KN} \cdot \mathrm{m}$
Also, it can be seen that the overall stability factor $\varphi_{b}$ of welding beams is lower than rolled beams. Thus, the design value of critical moment of welding beams is lower than rolled beams.

(2) GB 50017-2003

According to B.1-1 in Appendix B in GB 50017-2003, we can get $\eta_{b}=0.288$. Then substituting into the formula(6):

$$
\begin{aligned}
& \varphi_{b}=\beta_{b} \frac{4320 A h}{\lambda_{y}{ }^{2} W_{x}}\left[\eta_{b}+\sqrt{1+\left(\frac{\lambda_{y} t_{1}}{4.4 h}\right)^{2}}\right] \frac{235}{f_{y}}=8.13>0.6, \\
& \varphi_{b}^{\prime}=1.07-\frac{0.282}{\varphi_{b}}=1.0
\end{aligned}
$$

The design value of critical moment is:

$M_{X} \leq \varphi_{b}^{\prime} W_{x} f=1.0 \times 2758.6 \mathrm{~cm}^{3} \times 215 M P a=593 \mathrm{KN} \cdot m$

(3) AISC 360-10

Also $\beta_{b}=1.667$.

$L_{b}=450 \mathrm{~cm}, L_{p}=1.76 r_{y} \sqrt{\frac{E}{F_{y}}}=381.4 \mathrm{~cm}$,

$r_{t s}=\sqrt{\frac{\sqrt{I_{y} I_{w}}}{W_{x}}}=8.7 \mathrm{~cm}$

$L_{r}=1.95 r_{t s} \frac{E}{0.7 F_{y}} \sqrt{\frac{J_{C}}{S_{x} h_{0}}} \sqrt{1+\sqrt{1+6.76\left(\frac{0.7 F_{y}}{E} \frac{S_{x} h_{0}}{J_{C}}\right)^{2}}}=1029.6 \mathrm{~cm}$ is:

Because $L_{p}<L_{b} \leq L_{r}$, so the formula of critical moment

$$
\begin{aligned}
& M_{c r}=\beta_{b}\left[M_{p}-\left(M_{p}-0.7 F_{y} S_{x}\right)\left(\frac{L_{b}-L_{p}}{L_{r}-L_{p}}\right)\right]=1240.6 \mathrm{KN} . \\
& m>M_{p x}=776.5 \mathrm{KN} \cdot \mathrm{m} \\
& \text { Because } \quad \text { when } L_{p}<L_{b} \leq L_{r}, \quad M_{c r} \leq M_{p x}, \quad \text { so } \\
& M_{c r}=776.5 \mathrm{KN} \cdot m
\end{aligned}
$$

Substituting into the formula(12):

$M_{X} \leq \phi_{b} M_{c r}=0.9 \times 776.5 \mathrm{KN} \cdot \mathrm{m}=698.9 \mathrm{KN} \cdot \mathrm{m}$

So the design value of critical moment is $698.9 \mathrm{KN} \cdot \mathrm{m}$.

\section{CONCLUSIONS}

We can draw the following conclusions from the example in Fig. (5):

(1) From the aspect of calculation thought, the specifications between China and USA are different. GB 50017-2003 and GB 50017-201X first translate the critical moment $M_{c r}$ into overall stability factor $\varphi_{b}$, then doing the overall stability design by $\varphi_{b}$; while in AISC 360-10 critical moment $M_{c r}$ is used for overall stability design directly. 
(2) For the determination of equivalent moment factor $\beta_{b}$, GB 50017-2003 has been using the lower limit (formula 3 ) in equivalent moment factor $\beta_{b}$ curve of hinged nonuniform flexural members which was got by M. G. Salvadori in 1956 and the Table B.1 in Appendix B based on the formula. The overall stability design formula of GB 50017-201X does not involve the calculation of $\beta_{b}$ after changes. AISC $360-10$ got the formula of $\beta_{b}$ (formula 11) by the moment distribution map of unbraced length beam segment which was proposed by P. A. Kirby and D. A. Nethercot in 1979 and making some corrections afterwards. So it can be clearly seen that the determination thought and calculation formula of $\beta_{b}$ are different between the three specifications.

(3) This is distinctly different that GB 50017-2003 and GB 50017-201X use the design strength $f$ while AISC 36010 uses the yield strength $f_{y}$ in overall stability design formula.

(4) In the process of overall stability design, GB 50017-2003 and GB 50017-201X uses the elastic resistance moment of section $W_{x}$; however, AISC 360-10 not only uses the elastic resistance moment of section $W_{x}$ but also uses the plastic resistance moment of section $W_{p x}$ morely.

(5) GB 50017-2003 does not distinguish the overall stability factor $\varphi_{b}$ between welding beams and rolled beams. The formula of $\varphi_{b}$ mainly refers to the test data of rolled beams in GB 50017-2003. AISC 360-10 also does not distinguish welding beams and rolled beams in overall stability design. However, GB 50017-201X distinguishes the overall stability factor between welding beams and rolled beams by referring to the research achievements of UK and Japan in this respect. In the example of Fig. (5), firstly for the doubly symmetric cross section, the design value of critical moment is $641.7 \mathrm{KN} \cdot \mathrm{m}$ by GB 50017 2003; while in GB 50017-201X it is $670 \mathrm{KN} \cdot \mathrm{m}$ (rolled) and $645.6 \mathrm{KN} \cdot \mathrm{m}$ (welding); then for the singly symmetric cross section, the design value of critical moment is $593 \mathrm{KN} \cdot \mathrm{m}$ by GB 50017-2003; while in GB 50017-201X it is $622.8 \mathrm{KN} \cdot \mathrm{m}$ (rolled) and $614.7 \mathrm{KN} \cdot \mathrm{m}$ (welding). So it can be seen that the design value of critical moment by GB 50017-201X is slightly increased compared with GB 50017-2003 and the difference is very small. Besides, in GB 50017-201X the design value of critical moment of welding beams is lower than rolled beams because the overall stability factor $\varphi_{b}$ of welding beams is lower than rolled beams. In addition, the design value of critical moment by AISC $360-10$ are $702.8 \mathrm{KN} \cdot \mathrm{m}$ and $698.9 \mathrm{KN} \cdot \mathrm{m}$ for the doubly symmetric and singly symmetric cross section, so it can draw the conclusion that the design value of critical moment by GB 50017-2003 and GB 50017-201X is conservative and safe compared with AISC 360-10.

\section{CONFLICTS OF INTEREST}

The author(s) confirm that this article content has no conflicts of interest.

\section{ACKNOWLEDGEMENT}

None declared.

\section{REFERENCES}

[1] Z. Zhaoquan, "A Brief Analysis of Stability about Steel Structural Members”, Steel Construction, vol. 26, no. 144, 2011.

[2] GB 50017-2003, "Code for design of Steel Structures", China Planning Press: Beijing, China 2003(in Chinese).

[3] GB 50017-201X, "Code for design of Steel Structures (exposure draft)", National Standards Management Group of Code for design of Steel Structures: Beijing, China.

[4] AISC 360-10 Specification for Structural Steel Buildings[S].

[5] M. G. Salvadori, "Lateral Buckling of Eccentrically Loaded IColumns”, Transactions of the ASCE, vol. 121, pp. 1163-1178, 1956.

[6] T. Genshu, "Out-of-plane stability of steel structures” China Building Industry Press: Beijing, China, pp. 137, 2007.

[7] Chen Ji, "Stability of steel structures theory and design", Science Press, pp. 349, 2003.

[8] Chen Ji, "A comparison of stability design of bending members by specifications for design of steel structures in various countries", Industrial Construction, vol. 39, no. 6, 2009.

[9] (USA)Wenacotta writing, Chen Zhihua translating. Performance of Steel structures and LRFD specification [M]. Huazhong Science and Technology University Press, 2011: 295.

\footnotetext{
Received: July 23, 2013

Revised: October 15, 2013

Accepted: October 18, 2013

(C) Kongpei and Wanli; Licensee Bentham Open.
}

This is an open access article licensed under the terms of the Creative Commons Attribution Non-Commercial License (http://creativecommons.org/licenses/ by-nc/3.0/) which permits unrestricted, non-commercial use, distribution and reproduction in any medium, provided the work is properly cited. 